As to the different instruments used I am inclined to prefer Thompson's divulsor, as it produces the greatest dilatation at the point where it is most needed. In conclusion, I may say that so far as my experience goes, I see no reasun for preferring the slow and tedious process of gradual dilatation to the more rapid measures, and in all cases of traumatic stricture, or of stricture complicated with fistulx, I believe the perineal section affords the most satisfactory results.

\title{
TWO CASES OF STRICTURE OF THE URETHRA. ${ }^{1}$
}

BY J. FOster busir, M. D. HaRV.

CAsE I. The patient, a man aged thirty-nine, has the following history. When twenty-five years old, in 1860, he contracted gonorrhoea, the symptoms of which, according to his statement, did not come on until six weeks after connection. This urethritis lasted for some three months, and was accompanied by excessively painful chordee. Injections were the chicf remedies used. Upon getting fatigued or upon exposure to cold and damp a slight discharge would again come on, not enough to cause alarm or great discomfort, and no action was taken in the matter until three years later, when, having serious trouble in micturating, ho consulted a physician, who upon examination detected a stricture in the membranous portion of the urethra. This stricture was divided by the urethrotome; no after-treatment was carried out, and in a short time ho was as bad as before, and eighteen months after, in 1865, he was operated upon at Bellevue Hospital, New York. Holt's dilator was used, but, as in the first instance, no after-treatment was followed up, and $t$ is operation also proved unsuccessful, the patient in fact being worse off on account of the increased inflammatory action set up. In 1867, two years later, after repeated attacks of retention and a threatened perineal abscess, he ontered the Massachusetts General Hospital, where perineal section was performed, and a No. 8 English catheter was fastened into the bladder. The wound healed quickly and he felt decidedly better, and for a time after leaving the hospital passed the instrument that was furnished him, a bougie; but this getting worn out, he destroyed it and did not replace it with another, as he felt perfectly well and the necessity of passing an instrument continuously had not been enforced upon him. In 1871 and 1872 he lived in Kansas, and while there was perfectly free from urinary trouble. In 1873, upon his return to Boston, he began to have at irregular intervals attacks of cystitis and retention, and to relieve the latter he was instructed how to pass an instrument. He remained in a very uncomfortable condition, at times able to be up at work, and at other times in bed, until 1874, when I

1 Read before the Boston Socioty for Medical Observation, A pril 3, 1876. 
saw him. He was then suffering from repeated attacks of retention, which were relieved by morphine and by the passage of a small bougiecatheter. After hearing his history I advised another operation, but, his experience of such proceedings being somewhat more extended and varied than that of most men, he declined. I explained to him that the operation was by no means as important as the after-treatment, and that in order for it to do any good, the passage of an instrument must be carefully and persistently followed up. He desired to see Dr. George H. Gay in consultation. This was done on November 16th, and as Dr. Gay agreed with me that surgical interference of some kind was necessary, the patient gave his consent. Ether was administered and Holt's dilator was used. The stricture was very elastic, giving way before the instrument like India-rubber, and although the largest-sized dilator was used it was with difficulty that a No. 6 English elastic catheter could be passed through into the bladder and fastened in. This catheter was allowed to remain in for forty-eight hours, at which time, there being a slight purulent discharge from the meatus, it was removed. For three days no attempts were made to pass an instrument, thus giving the urethra an opportunity to heal. At the end of this time a No. 10 bougie (French scale) was passed without producing much pain. This was done morning and night for a week, using a larger bougie each day until a No. 17 was used. A nickel-plated steel sound (No. 12) was then made. At first there was great pain upon its introduction, but the urethra soon became accustomed to its presence. At first this sound was passed every day, then every second day, and then only once a week. With the practice the patient had had with soft instruments he was soon able to master the sound, and now he passes it every seventh day. It is now seventeen montlis that he has used it, and he has become so accustomed to it that it causes him no inconvenience, and he declares that it will not be his fault if the stricture troubles him again.

Cass II. The second case is taken, by permission, from the records of the Massachusetts General Hospital, the patient being there while was surgical interne at that institution. It is one of a series of eight divulsed with Voillemier's dilator by Dr. Hodges, all having more or less the same history, and all having been operated on once at least before entrance, at which time, however, no after-treatment had been carried out. Almost all entered for relief from retention. Some of the cases were of traumatic origin, but most of them followed gonorrhœa. After operation all were furnished with sounds, were instructed how to pass them, and were cautioned particularly about keeping up the practice, being told that a return of the stricture would take place if they neglected it. They were requested to report from time to time, especially if they experienced any trouble. For a year I was able to trace most of them, and they sent good reports. Two of the cases 
live in the city, and they keep up the practice and experience no trouble, as I know from a recent examination. Instead of taking the whole eight cases and reporting them at length, I will take the following, which will answer all purposes for illustration of the principle and save tedious repetition.

G. M., aged forty, while on a foraging expedition during the late war, was thrown from a wagon, striking astride one of the wheels, injuring his perinæum quite severely. He was confined at a field hospital for some time, and had an instrument kept in the bladder. Upon resuming his duties he experienced no great trouble until about a year after, when, fording a stream one wet, autumnal day, he became thoroughly chilled and was attacked with retention. As opiates did not produce the desired effect and as an instrument could not be passed, perineal section was performed by the regimental surgeon. The wound was a long timo contracting, owing to unfavorable surroundings, and for quite a period he was troubled with a perineal fistula, which, however, subsequently closed. No after-treatment was enforced. Upon his discharge from the army he came North and lived in New Hampshire. Here at times he would be in perfect health, and at others, as is the case with all subjects of stricture, he would be perfectly miserable. Suffice it to say that he continued in this way, losing flesh and strength, and unable to work much. In one attack of retention, his physician not being able to introduce a catheter or to produce the desired effect with morphine, the patient was tapped over the pubes by the aspirator. This was repeated for three successive days, at the end of which time he entered the hospital, being able then to pass a little water at a time. He was etherized upon entrance, and the introduction of an instrument was attempted; although the greatest care and perseverance were used it was found impossible to do this, for although the bougie was firmly held by the stricture it could not be made to go through. Attempts were therefore no longer made, and the patient was put to bed and kept under the influence of morphine given in the form of suppositories. Three days after this attempt another attack of retention came on, which was relieved by morphine hot baths and the pressure of a bougie against the stricture. The next day ether was again administered, and it was decided if a capillary bougie could not bo passed to perform perineal section. This time, however, fortune favored the exertions, a filiform bougie was introduced, Voillemier's rupture-instrument was brought into play, the stricture was divulsed, and a No. 12 English elastic catheter was fastened in as usual. This was removed on the second day, and no passage of an instrument was attempted for some time, as the patient suffered from repeated chills, high temperature, frequent micturition, and purulent urine. When this exacerbation of cystitis had subsided, the passage of an instrument was attempted. At first this was 
excessively painful, but soon the urethra became accustomed to it, and the patient was able to pass it himself. He was furnished with a nickelplated stecl sound (English No. 12), was cautioned to keep up the practice, and was sent on his way rejoicing. I heard from him a short time ago. He still uses the sound occasionally, and enjoys excellent health.

These cases are reported simply to illustrate what is already a wellrecognized fact, which all the authorities, save Dr. Otis, state in the same emphatic manner. These and many more similar cases from hospital records show a point upon which sufficient stress is not laid, namely, that the operation for stricture of the urethra does no good unless the after-treatment, the continual passage of a sound or bougie, is faithfully carried out, and that if we are not watchful in so doing, the inflammatory action will again get the upper hand and will make the case as bad if not worse than before. The first of these cases shows this particularly well, for previous to the last operation, when this principle was carried out, the patient had had the stricture cut from the inside by the urethrotome, from the outside by perineal section, and had had it divulsed, with always the same unfavorable result. In the second case this passage of an instrument ought to have been particularly enforced upon the patient at the time of the first operation, for his stricture was of traumatic origin, and, owing to its more extended character, it was more likely to contract. Concerning cases of this kind Van Buren and Keyes, in their Genito-Urinary Surgery, say: "Traumatic strictures are particularly liable to be sensitive, irritable, and resilient, and usually require harsher means of treatment than ordinary dilatation and the employment of more persistent and intelligent measures to prevent recontraction afterwards than most strictures from other causes. Hence the imperative importance in these cases of insisting upon an intelligent use of the full-sized steel sound, by the patient himself, for an indefinite period of time after a cure, generally for the remainder of life; a task certainly irksome and disagreeable, but no more so and no less necessary than a truss to the ruptured, spectacles to the weaksighted, an artificial leg to replace the amputated one, and certainly more necessary and less irksome than the daily use of the razor."

\section{RECENT PROGRESS IN GENITO-URINARY SURGERY.}

BY THOMAs 1 . curtis, M. D.

The Treatment of Advanced Prostatic Disease. - A year ago Sir H. Thompson's procedure for the relief of patients suffering from prostatic hypertrophy which has arrived at its last stage, with retention of urine, cystitis, and diminished capacity of the bladder, was described in this report. It consists in the introduction into the bladder, above the

1 Boston Medical and Surgical Journal, December 30, 1875, page 766, 